\title{
The Analysis of Threats and Opportunities in Sustainable Irrigation Development in Lesotho
}

\author{
${ }^{1}$ Moses M. M. Daemane*, ${ }^{2}$ Israel, Peace Chinwendu \\ ${ }^{1}$ National University of Lesotho, Lesotho \\ 2University of Education, Winneba, Ghana \\ *mosesdaemane@gmail.com
}

\begin{abstract}
This paper analyzes threats and opportunities in sustainable irrigation development in Lesotho. The addressed research question is what threats and opportunities are there in irrigation projects backed by the government of Lesotho (GoL) for sustainable development and income generation in the rural areas for subsistence farmers. Threats to irrigation projects pose a problematic situation with a high possibility for project failure in attaining sustainable development. They need to be analytically identified for the provision of solutions at the project planning, implementation, monitoring and evaluation processes. The study has adopted the in-depth interviews for problems and opportunities identification with the participation of 63 irrigating farmers as respondents. Revealing threats against opportunities enable proper irrigation projects planning and implementation and therefore successful and sustainable irrigation development in Lesotho. Indepth field interviews'findings are on farmers in eight project sites selected by the Ministry of Agriculture (MoA) for further irrigation development with the backing of Food and Agricultural Organization (FAO). The eight sites are (1) Semonkong Ha Lesala and (2) Semonkong Ha Sechache, in Maseru district, (3) Ha Rasekila in Butha-Buthe district, (4) Qopo Ha Molefi in Berea district, (5) Maphutseng in Mohale's Hoek district, (8) Qhoalinyane Ha Semethe and (7) Qhoalinyane, in Qacha's Nek district, and lastly (8) Ha Makoae in Quthing district. The main implementing agency for this Water Control Component of the Special Programme for Food Security is the MoA in Lesotho.
\end{abstract}

Keywords: Sustainable Irrigation Development, development, development planning. Sustainable development, irrigation projects' threats, irrigation projects' opportunities

\section{Introduction}

This research paper has to an extent adopted some threats and opportunities analysis approach with the aim of providing the analysis of threats and opportunities in sustainable irrigation development in Lesotho. The paper provides analytic insights and lessons essential for proper planning and managing of sustainable irrigation projects. As thus, the paper covers threats and opportunities in irrigation in Lesotho. That is constraints and potential for food production related to GoL's irrigation project for sustainable development and income generation in the rural sector. Firstly, the study dwells on the weaknesses and threats or constraints. Secondly, on the climatic and ecological hazards. Thirdly on the environmental risks, topography and soil issues, cultural practices in farming, inputs' problems and policy constraints, land tenure issues, extension support, strengths and opportunities and required irrigation projects' expertise in order to achieve sustainability in irrigation development and income generation in the rural sector.

Weaknesses and Threats/Constraints: The general weaknesses before coming to specific ones in the current irrigation situation still include poor techniques of soil moisture conservation so as to be cost effective on irrigating water charges and ensure 100 percent germination. Schemes tend to ignore the fact that farmers are heavy laden with high water charges and are not trained and helped with techniques of moisture trapping and regulation. Our irrigation competes with high evaporation. This weakness and problem serve as a constraint even to the production of seedlings (e.g. of cabbage). The project will have to provide facilities for seedlings production to every scheme if not to every farmer. Furthermore, nationally, schemes still traditionally believe in the need for more arable land for expansion, not worst but other techniques/technologies are not talked of, food is no longer a soil product of massive lands only, it can be a glass, greenery coverings, plastic and so on product if Lesotho is to compete in the world market or attain food security since massive lands are not part of our comparative advantage. After all if you do not get 
prepared to compete in the global market, then other than being a sustainable competing beneficiary in globalization, the global market responding to only cash backed needs will stifle local production efforts (the Owolo case in Ethiopia) causing food-insecurity and dependency because cash has a skewed distribution. What is needed is intensified land utilization, possibilities of arable land expansion for irrigation may not hold on in the long-run, though they also still need to be exploited (GoL's Reports, 1999, and 2000-2007 and Swot Analysis In-depth Interviews Survey, May, 2014).

Techniques of improving germination and emergence are not applied, selective strategic use of relevantly high yielding hybrids is not done, and farmers simply buy any improved seed. Even improved seeds perform differently in different situations. This is where our research activity service delivery is not yet widely effective as constrained by lack of adequate infrastructure and difficult terrain in efforts to diffuse knowledge, technologies and innovations/improved practices. Knowledge on the choice of hybrid seeds with better local climate tolerance and better yield on the part of irrigating farmers is not thorough and calls for improvement. Seedbed preparation for good soil layer for better yield is not yet a widely maintained working idea. Lacking tractor resource contributes to this poor practice, creating absence of optimum planting depth. The project needs to assist every scheme with sustainable tractor hiring financial arrangement or let each project site have access to or own at least two tractors. Financial arrangement made should be able to maintain the tractors, their drivers and mechanics structurally put in place. Farmers also lack adequate protective clothing and equipment for applying chemicals. Project stores in the schemes may need to be supplied with the protective clothing, equipment and chemicals for farmers to buy and use. This can facilitate control on the use of chemicals that may badly affect the environment and the users. Pricing will need to be competitive (Swot Analysis In-depth Interviews Survey, May, 2014).

Generally, a number of types of irrigation methods can be applied in the irrigation project sites but development project planners have a saying that definite failure of development projects is always due to lack of commitment on the part of the beneficiaries and their agency/public support/government in terms of observing schedules for implementation, joint stakeholders involving budgeting process and agreed upon performance goals and monitoring indicators. Delayed implementation and unsustained support affects momentum of participation and production negatively. Lack of commitment by farmers and the government is a historic feature in the irrigation development of Lesotho. This has been worsened by inappropriate design including irrigating systems that lack durability, simple maintainability by the farmer and not taking advantage of the homes' security and the topography of the country, which is gravity systems operated by sustainable environmentally safe cheap sun's power. Irrigation schemes in Lesotho have been characterized by lack of effective maintenance and poor financial and economic viability. Projects that do not connect to global market trends competitively through agribusiness and industrialization are never at any war to win, not to talk of poverty alleviation and food insecurity. Nevertheless, this is not a panacea but it can create better opportunities and achievements (Swot Analysis In-depth Interviews Survey, May, 2014).

Climatic and Ecological hazards: Late and early frosts, occasional hailstorms, high intensity rainfall with thunderstorms, low rainfalls, snowfalls and too low untimely temperatures are the climatic constraints reported to be affecting irrigated vegetables production. The project activiti9es will be badly affected by these climatic constraints if the exact number of days of growing plants (safe growing period) is not made known to the farmers. Cold-sensitive plants may also need to be strategically in the light of such safe growing period. This strategic knowledge has to help in the production of fruits as in some schemes there are fruit trees at all and yet there are species of the same fruit trees planted in Lesotho that can, to a certain degree, thrive in cold weather. Research services from MoA have to benefit the project in this aspect. This has to include knowledge impartation to farmers about plants or vegetables that are relatively more cold resistant than others. Such knowledge needs to be backed with inputs availability for farmers' use. According to table 2.10, farmers know the times pests invasions are rife. Stock supply on pesticides therefore needs to be made more available around such times (Swot Analysis In-depth Interviews Survey, May, 2014).

Drought is said to be one of the main constraints in dry land farming but RSA's farmers along the border of Lesotho under the same climatic conditions are able to produce high yield. Techniques and inputs necessary to preserve adequate moisture in the soil even under severe shortage of rainfall need to be made known and available to the farmers. There are inputs that can supply some periodic moisture to the soil for the benefit of 
plants' production even under severe dry conditions. Various international reports show Israel to be lacking in much rainfall but able through moisture preserving techniques and intensive land utilization to feed even its neighbours. These moisture content preserving techniques and inputs need to be learned and appropriately applied in the right context for the benefit of Lesotho. The problem is so far not drought but poor moisture preserving farming practices and lack of such techniques and inputs. Knowledge is power/victory, not the constraints/challenges (Swot Analysis In-depth Interviews Survey, May, 2014).

Environmental Implications/Risks: Land reclamation/rehabilitation and soil and water conservation methods will have to be included in the activities of the irrigation projects in Lesotho. Some fields are prone to erosion requiring deliberate project efforts to preserve the environment. Probably the main environmental challenges include soil erosion, uncontrollable weeds and soil acidity especially in the lowlands. Low soil fertility and soil diseases worsen this. It is true that farmers mentioned some of their soils to be of good colour but unfortunately marred with poor yields. Farmers also reported some of their fields to be having small gravel stones disabling successful germination. There is need to embark upon conservation activities, especially for the fields by the rivers used for irrigation. Otherwise, some fields will be completely eroded right within the irrigation area. It would be best to implement conservation activities that are also directly productive like fodder producing to curb soil erosion and improve the rangeland or pastures. Such fodder for soil preservation can always be cut to generate income. Most of the fodder in use is the imported one. Water logging, leaching and salination are also the risks to be controlled under irrigation projects. These risk factors need to be controlled through use of good regulatory technology, frequent periodic soil testing and appropriate treatments like lime application (Swot Analysis In-depth Interviews Survey, May, 2014).

Topography: The other environmental challenge to be faced by the project is that one of fields on the nonflat areas. A number of fields are on sloppy, undulating and flat-less land. These lands are prone to run-offs from stormy rainfalls. The kind of topography faced with in a number of fields owned by farmers, especially under dry land farming, makes the soil to be prone to sheet erosion, gully erosion and possible splashes that can erode plants themselves. This is to be the case because the country is mountainous or has many hills. Proper ploughing and planting methods need to be imparted to farmers through the extension agents. This should not be a serious constraint in horticulture. Soil can be prepared quite well under these conditions and be preserved (Swot Analysis In-depth Interviews Survey, May, 2014).

Soil issues: Soils on many fields, as observed and farmers interviewed, besides being erodable and acidic are of low fertility and have low levels of nutrients for plants. They have too little moisture and seem to lack long water holding capacity from their texture and structure. Water quickly seeps through due to low water retainment capacity. These soils dry quickly in the face of the scorching sun of Lesotho. The project for food security will always be faced with the requirement of improving soil fertility, nutrients, neutralizing acidity of the soil and providing inputs that add some lasting moisture to the soils especially under dry land farming or traditional rain fed farming. Farmers need to be encouraged more on practices of not only kraal manure and fertilizer use but also on compost heap and wood ash manure. These two latter ones are not used in the schemes, particularly composed heap (Swot Analysis In-depth Interviews Survey, May, 2014). A practice of using crop residue as animal feed is still widespread. There is a need for irrigating project to train farmers more on soil nutrients replenishing practices, other than 'soil mining' through crops. This is a particular need for fields under dry land farming. Soil erosion reduces soil depth adequate for lasting moisture but this is worsened by poor ploughing methods creating a thin erodable soil layer not enough for roots covering and moisture provision to plants (Swot Analysis In-depth Interviews Survey, May, 2014).

Cultural practices: Gender-wise, women have a problem of having to be out of productive activities for some time due to cultural mourning practices in the loss of spouses or close family members (biological children). They are socially expected to reduce their involvement with public or productive activities after early weeks of marriage, biologically constrained by some period of expectancy, family caring role and lastly by the mourning attire to be dressed for some months in case of death of the spouse or close relative, expected to be least active in public works. Somehow, this misses the real intent of mourning cloth. It affects production as it reduces labour supply. Irrigating schemes also have to develop a business culture of being immune through advocacy against counterproductive holding at ransom cultures like not going for irrigation work because work abstinence is to be observed by all when any one far away has passed away. In a rural community at the 
moment, of course, locals need to attend burial ceremonies because there are no funeral agencies to dig graves and do other burial services but does this compulsorily need every member of the family in the community to attend the funeral thereby stopping everything including mere crops selling in the fields by other farm labour providers of the family. Only that this has to be revisited and reviewed by the involved communities in the light of the fact that schemes have farmers coming from afar villages renting fields for irrigation and not knowing who the diseased is, family labour is limited in number and is faced with the risk of frost requiring early finish in planting. Furthermore, the culture of all having to attend the Pitso (public gathering) called by the local chief on issues that directly have nothing to do with the schemes is seen as a time delaying and wasting constraint. Some farmers have asked why it is not a case that when someone is gone off for a different work he or she is not called back to attend the Pitso. Others said it is better for the chief to come and address them on the irrigating farms if issues are on irrigation, if not, leave the workers to work. There was a suggestion that it could always be better to send a scheme's representative to such Lipitso who can come back to report at the structured meetings of irrigating farmers (Swot Analysis In-depth Interviews Survey, May, 2014).

Farming is still culturally extensive, characterized by low input and output for subsistence. Inputs are still being recycled, especially in dry land farming. This traditional rain fed production system though unreliable and inadequate is still relied upon. Practices in production are still a gamble against climatic conditions. The real issue is that irrigating projects need to take into account and plan against the lack of farmers' knowledge and effective skills in dry land farming. Draught animals are still in main use and implements/technology used is still too laboured intensive and not intensively productive. It is best to have an irrigation policy supplemented with mechanization and other productive policies and programmes (Swot Analysis In-depth Interviews Survey, May, 2014).

Inputs' problems and policy constraints: In this liberated market, dealers/input suppliers only go to where there is the possibility of profit maximization. The free market does not respond to needy people who do not have enough money for inputs, it responds to cash-backed needs. Rural needs are not cash backed and do not provide high profit margins and good turnover in sales. They are just a needy people with extensive fields. In the economic context where 80 percent of the population is rural dwellers and national unemployment is 40 to 45 percent, then rural underemployment, under-productivity, higher unemployment worsened by RSA's mines retrenchment, increased poverty and food insecurity do become almost insurmountable problems which the rural dwellers cannot solve by themselves. These farmers lack capital resources and inputs and the free market rationally neglects them (Swot Analysis In-depth Interviews Survey, May, 2014).

If then irrigation is to be successful in Lesotho, there is need for an effective input policy and strategies to overcome its usual weaknesses seen in other countries including state's institutions' impropriety, political bias in distribution of inputs, inefficient delaying inputs delivery systems resulting in loss of appropriate time for planting, misappropriation of funds for inputs, biased distribution of inputs by public officials, high inputs' storage costs, theft and corruption in accessing inputs, misapplication or improper application of inputs by farmers, inputs non-application by farmers whereby we see them wasting in the open/countryside in these other countries. The irrigation project has to make sure that input packages are a quantity needed and ordered by the farmers themselves. Planning for this has to be done based on a three-year rolling plan ahead of the planting year's season to minimize delivery failures. Cost recoupment through farmers' produce needs to be integrated and the whole process of scheduling, budgeting and setting of goals needs to be driven by the farmers. Everyone else may need to be but a facilitator and a supporter. The reason why many donors preferred to directly fund communities or NGOs in the communities was among others to by-pass the 'red tape'. However, other donors have preferred to control the budget within a well community empowering development process but involving the public institutions for more resources harnessing. Procedures for input delivery and distribution may need to be implemented by the beneficiaries themselves through their own organizations, structures or institutions. Government support, facilitating and overseeing are still very important contrary to absolute public officials' control and farmers' non-involvement (Swot Analysis In-depth Interviews Survey, May, 2014).

Land tenure: The land tenure system is traditional communal land tenure allocated by the Village Development Councils. Land cannot serve as collateral to access more inputs for commercial production. It is 
in other way collateral. Farmers possessing a lot of this land are as good as any other penniless person. They cannot easily transform to commercial farmers. It could be best for the project to internally and locally solve this aspect by making such arrangements that will enable farmers to borrow against their fields as assets that can be planted as many times as worth the loan in cash or in kind taken by the farmer. Loan repayments may also be done through sharecropping with farmer. This could also be highly helpful in dry land farming including irrigated vegetables production (Swot Analysis In-depth Interviews Survey, May, 2014).

\section{Extension support and methodology}

All the project sites have at least one extension agent (EA). Extension support is currently demand-oriented. The advice-method to influence farmers' adoption is the one mainly used method. In many developing countries, the EAs are usually de-motivated by low remuneration, untimely transfers or transfers used as a form of demotion or a sanction at workplaces. They are working in an environment that has limiting factors like inadequate transport, few or no rest houses for moving around an extension area to effectively be with the farmers to advise them. It is important that transport facilities provided to extension agents be of userfriendly simple to maintain facilities. The mode of transport also need not put extension agents at a difficult position to interact with the farmers. Evaluation done in one development project unearthed that farmers find EAs quite inaccessible and not easy to stop for any discussions in their fast moving vehicles. Using a local user-friendly maintainable mode of transport promotes rapport between the EAs and the farmers. Rapport facilitates effective communication that is important in receiving, understanding and adopting imparted knowledge, technologies and innovations. Basic infrastructure like housing, communication facilities and other basic support services are important for EAs' effective delivery (Swot Analysis In-depth Interviews Survey, May, 2014).

Strengths and opportunities/Potential: Opportunities in irrigation development in Lesotho are unlimited. Immediate socio-economic opportunities include self-employment creation by the farmers, women's selfdeterminism from income earned, agribusiness and agro-industrialization enabling processing, value adding and product diversification services to supply the global/international market for foreign exchange earnings. Schemes have to own income generating and service providing assets as a move towards capital formation and accumulation. Crops production at the moment only contributes 7 percent to the national GDP and yet industrialization is fast growing. A way to close this gap is to open our agricultural products to foreign markets and let the agricultural sector industrialize as well to create more employment opportunities. The process and an opportunity of agrarian transition in Lesotho like in other countries through facilitated capital accumulation and effectively organized local and international marketing (Swot Analysis In-depth Interviews Survey, May, 2014).

Better, farming systems like intercropping (Machobane) farming system in Soil and Water Conservation and Agroforestry Project (SWaCAP) and the low-pressure micro-scale irrigation system and community garden development in the Local Initiative Support Project (LISP) are not yet widely and intensively applied. Irrigation development provide a better opportunity for transformational development and poverty alleviation as well as formulation and effective application of policy programmes beneficial to the country including strategic input policy, irrigation policy, mechanization, research, pricing, credit and others enabling determination of the level of development, farmers' income, technology adoption, improved consumptions, health levels, food security and others. Furthermore, there is an opportunity of soil conservation activities/land reclamation and fodder production actually leading to rangeland improvement. Irrigation development can facilitate crops diversification, intensification and by-products manufacturing. It would be best for the planned project activities to include the above views and expectations from the farmers (Swot Analysis In-depth Interviews Survey, May, 2014).

\section{Conclusion}

This swot (strengths, weaknesses, opportunities and threats) analysis paper covers threats and opportunities in sustainable irrigation development for sustainable rural income in Lesotho. That is constraints and potential for food production related to GoL's irrigation project for sustainable development and income generation in the rural sector. The study dwelled on the weaknesses and threats or constraints and on the 
climatic and ecological hazards, the environmental risks, topography and soil issues, cultural practices in farming, inputs' problems and policy constraints, land tenure issues, extension support, strengths and opportunities and required irrigation projects' expertise here below in order to achieve sustainability in irrigation development and income generation in the rural sector.

Based on the above findings the research has revealed that for irrigation development to remain sustainable and generate income in the rural areas continuously there is required expertise. Farmers are already happy with the extension agents available. They have pointed to the need to have someone who can regularly test their soils for better treatment. Farmers suspect that their soils have some diseases that cause irrigated vegetables to just wither. The strong feeling is that a soil scientist is needed. One other desperate technical person mentioned to be needed by farmers is one who can quickly repair the broken water pumping machines to cut on losses made by a long waiting time to repair the irrigating systems. While farmers are contented with their extension agents, there is a strong feeling among them that an evaluation person would be very important for attaining feedback on performance and produce monthly management reports and seasonal reports on agreed upon monitoring indicators. Since solar panels may be used to augment irrigating gravity systems then electrical and mechanical engineers are needed (Swot Analysis In-depth Interviews Survey, May, 2014).

\section{References}

Government of Lesotho/GoL. (1999). National Livestock Development Study. Technical Report C.2. Maseru: Kingdom of Lesotho

Government of Lesotho. (2000). National Livestock Development Study: Dairy Production, Milk Collection, Milk Processing and Marketing. Phase 1 Report Part II Technical Report D. Maseru: Kingdom of Lesotho

Government of Lesotho. (2001). National Livestock Development Study: Land Tenure and Land Use. Phase 1 Technical Report N. Maseru: Kingdom of Lesotho

Government of Lesotho. (2002). National Livestock Development Study. Technical Report E. Maseru: Kingdom of Lesotho

Government of Lesotho. (2003). National Livestock Development Study. Technical Report F.1. Maseru: Kingdom of Lesotho

Government of Lesotho. (2004). National Livestock Development Study. Processing. Phase 1 Report, Part II, Technical Report L. Maseru: Government of Lesotho

Government of Lesotho. (2005). National Livestock Development Study: Livestock Marketing. Technical Report H. Maseru: Kingdom of Lesotho

Government of Lesotho. (2006). National Livestock Development Study: Gender Issues in Livestock Development. Phase 1 Report, Part II, Technical Report L. Maseru: Kingdom of Lesotho

Government of Lesotho. (2007). National Livestock Development Study: Shortlisted Project Profiles. Phase 1 Report Part II. Maseru: Kingdom of Lesotho.

Swot analysis in-depth interviews survey on the irrigating farmers in Lesotho, May, 2014. 